This book, therefore, succeeds in providing the reader with simple derivations of many of the formulæ currently used in population and biometrical genetics. It falls down, however, in other requirements of an elementary text book. Thus while the careful reader will not be misled, the assumptions on which the derivations depend are not always explicitly stated. And since application of these formulæ, except to trivial examples is not attempted, the circumstances under which they may be appropriately applied is never discussed. The population genetics we should learn from this book neither asks worthwhile questions nor attempts to solve them by experimentation.

J. L. Jinks.

APICAL MERISTEMS. By F. A. L. Clowes. Oxford: Blackwell Scientific Publications. 1961. Pp. $217+32$ plates.

According to the dust cover of this book, "all the organs of plants develop from apical meristems, so that the study of these is equivalent in botany to the embryology of animals". An overstatement, no doubt; but the analogy is appropriate. Just because the apices of the higher plant are perpetually embryonic, they have long riveted the attention of cytologists, morphologists and developmental anatomists. For the same reason they are currently attracting more and more concern from physiologists and biochemists. A survey of what is known about apical tissues in general is thus to be welcomed at this time, and in this work Dr Clowes supplies it in modest space yet with accuracy and thoroughness.

The book falls into two halves, containing respectively treatments of shoot and root, the two poles of Bower's primitive spindle. For each type of organ, the available evidence is reviewed in considerable detail, especially in regard to the origins of tissue systems. In the section on the shoot, chapters are devoted to leaf initiation and development and the formation of buds, topics hardly to be divorced from a discussion of apical organisation and function. In the comprehensive treatment of the root, recent work on differentiation is summarised, and due consideration is given to the significance of Dr Clowes' own discovery, the quiescent centre of undividing cells seated so enigmatically in the heart of an active meristem.

The matter of tissue zonation has had more than its fair attention in anatomical studies of apices, and it is encouraging to see some debunking of facile "pattern-hunting" in this book. As Dr Clowes asserts, it is the pattern of division planes and its consequence in the disposition of cell lineages which is, if anything, significant in understanding the histological organisation of the apex. Of the recent theories of stem apical organisation that of Buvat has undoubtedly provoked the liveliest debate, with its curious Weissmannian implication that the stem carries aloft with it the safely sequestered méristeme d'attente, insulated during vegetative growth but ready at call to contribute its genetic quota to another generation. Observations and calculations of division rate, experiments with DNA precursors and the evidence of polyploid chimæras are, as Dr Clowes shows, sufficient to refute the suggestion that the apical cells of shoots do not divide; he concludes that the argument has now boiled down to semantics. Perhaps so ; but French can be an embarrassingly explicit language, and there are gallic contributions of recent date so phrased as to suggest that the issue is not dead yet. It is ironic that Dr Clowes has himself been accused of 
hankering after a méristème d'attente in establishing the presence of the quiescent centre in the root. The evidence for the latter is, however, secure; and its presence does not have such far-reaching developmental implications. The suggestions that the cells of the quiescent centre may have a functional role in maintaining the geometry of the root or as sites of hormone synthesis are interesting, for both hypotheses are open to test.

Notwithstanding Dr Clowes' concern to emphasise a dynamic approach to apical meristems, there are aspects of recent work which he conspicuously underplays. It is odd, for example, that he should give the impression that bud induction in tissue culture is not especially relevant to his theme; indeed he writes of Skoog's experiments as though they merely involve the awakening into activity of primordia that were already present, and not the initiation of buds de novo. Yet the demonstration by Skoog, Steward and others that an apex can be organised and a whole plant recovered from an initially homogeneous system of independent, dividing cells is surely one of the most remarkable botanical achievements of recent years. The prospects which the possession of techniques of this kind open up for the study of the origin of organisation in meristematic tissues are limitless. Then again, ultrastructural work bearing on the function of apical meristems is less fully covered than could have been desired ; there are important papers of earlier date than the latest quoted which receive no reference.

But to carp at omissions is less than fair when so much of importance is so excellently and clearly summarised. Perhaps a more justifiable cause for regret is that Dr Clowes did not find himself able to be a little less reserved in his conclusions and a little more speculative about the future of this field of investigation. It should be brilliant, with new techniques already to hand in dazzling array. But a student would not necessarily think it so from a reading of this book; paradoxically he might have some difficulty in locating the growing points.

\section{J. HesLop-HARrison.}

HEREDITY: AN INTRODUCTION TO GENETICS. By A. M. Winchester. New York: Barnes \& Noble, Inc. College Outline Series No. 58. Pp. 269. \$1.75.

An elementary introduction to genetics has a formidable list of requirements to fulfill. Its main needs are probably the following : (i) an historical foundation ; (ii) a presentation of the contrasting basic methods of investigation; (iii) examples of classical experiments with the steps in inference to be drawn from them ; (iv) notes of the important practical applications ; (v) illustrations of the raw materials, plant and animal ; (vi) diagrams explaining the processes and hypotheses which are supposed to be of prime importance.

Most of these requirements Dr Winchester's book meets unusually well. His accounts of methods and experiments are clear and instructive. His photographs of plants and animals are admirable. So are many of his diagrams. His introduction to statistics is modest but helpful. The whole book is humanly orientated with a generally satisfactory effect. And we can blame only the censor when the author, using a Klinefelter to illustrate underdeveloped male organs is forced to obfuscate these organs with a black triangle (p. 177).

The author is weak in those points where his predecessors have also 